Article

\title{
Self-Sufficient and Islanded-Oriented Design of a Reversible Solid Oxide Cell-Based Renewable Microgrid
}

\author{
Marco Sorrentino *(D), Antonio Adamo and Gianmarco Nappi \\ Department of Industrial Engineering, University of Salerno, Via Giovanni Paolo II 132, 84084 Fisciano (SA), Italy \\ * Correspondence: msorrentino@unisa.it; Tel.: +39-089964100
}

Received: 12 July 2019; Accepted: 14 August 2019; Published: 21 August 2019

\begin{abstract}
This article presents the development of a constrained optimization algorithm, whose scope is to support the preliminary design of a renewable microgrid, integrating solar panels and wind turbines with reversible solid oxide cells. The motivations behind this research activity lie in the increasing interest in renewable-based production and on-site storage of hydrogen, and its aim is to help this energy vector spread worldwide and in as many industrial and residential sectors as possible within a reasonably short timeframe. To this end, suitable models were developed by referring to the most relevant literature and by introducing some specific simplifying assumptions. Such an approach allowed the setting-up of a multi-variable constrained optimization task, whose outcomes correspond to the most techno-economic effective plant configuration with respect to assigned design criteria. The optimum solution was particularly sought via the generalized reduced gradient method, aimed at determining renewable plants sizes under the constraint that the final stored hydrogen level is brought back to the initial value after one year. The results highlight that an interesting payback time of about 10 years can be attained, while guaranteeing that the optimal configuration holds promising resiliency and islanded-use capabilities (such as almost weekly self-sufficiency) via smart over-the-year charge-sustaining management of the designed hydrogen storage tank. In this way, it was possible to simultaneously address, via the specific optimization problem formulation, the interconnected needs of optimally designing system components in terms of installed power, and the proper management of the reversible solid oxide cell unit.
\end{abstract}

Keywords: renewable energy; reversible solid oxide cell; fuel cells; hydrogen storage; constrained optimal design; resiliency

\section{Introduction}

The progressive increase in global energy requirements constantly pushes governments and involved researchers to find clean alternatives to traditional energy production methods. Damage to human health and the environment, increased greenhouse effect, lower availability, and higher prices are consequences of fossil fuel consumption that are in fact difficult to manage. The use of renewable energy sources (RES), which have the particularity of being clean and quickly regenerable, is now a viable solution due to related technological improvement. However, the progressive increase in the use of RES entails adopting adequate energy storage systems, so as to better adapt to the variability and uncertainty of power production. Currently, batteries are the most widespread; however, achieving the best compromise between performance and costs [1], limiting degradation [2], and avoiding overheating [3] still represent critical aspects. As for alternative storage devices, flywheel technology emerges as a suitable candidate, especially when high power density, fast response, and high efficiency 
are required [4]. Nevertheless, their high capital costs and low energy density are still important challenges to be solved, which currently limit their widespread adoption in renewable microgrids [5].

An efficient alternative for accumulating and converting surplus RES is to use reversible solid oxide cells (rSOCs) [6]; they enable both the storage of energy, in the form of hydrogen in solid oxide electrolyzer cell (SOEC) operation, and the conversion into electricity in solid oxide fuel cell (SOFC) mode. With respect to other reversible fuel cell technologies, rSOCs are particularly relevant due to their high round trip efficiency and cogeneration potential [7]. It is possible to use them in the industrial and electronics field and for vehicle propulsion, as well as in stationary generation and distributed combined heat and power [8]. The use of hydrogen allows the achievement of high-energy density storage, as well as guaranteeing supply for industrial processes according to actual needs. A key issue to be addressed, when aiming to effectively exploit the hydrogen energy vector potentialities, resides in the flexibility in the selection of the primary fuel; thanks to a reforming process, fuels such as natural gas, methanol, and biogas can be converted into hydrogen-rich gases. The fuel flexibility feature is indeed one of the main reasons that the adoption of solid oxide cell (SOC) technology is advantageous for stationary generation. When compared to reversible proton exchange membrane (PEM) fuel cells, the opportunity of feeding methane reformate in SOFC mode adds significant and beneficial flexibility to the design of cost-effective and low-carbon footprint fuel cell-based polygeneration systems [9]. Furthermore, it is worth remarking how versatile hydrogen is; beyond being the ideal fuel in PEM and SOFC systems, it can also be supplied to internal combustion engines [10] and gas turbines [11]. The fruitful combination of rSOC based stationary generation and fuel cell hybrid vehicles can also be significantly encouraged by hydrogen as an energy carrier, once appropriate vehicle design and energy management strategies are developed [12]. Furthermore, rSOC technology exhibits another significant feature, namely the generation of high-temperature useful heat, which can be exploited in a number of ways, thus further increasing the number of degrees of freedom, as well as allowing improved cost-effectiveness by meeting a larger variety of loads. Beyond combined heat and power applications, the heat produced in SOFC mode can be exploited to achieve the thermoneutral operation of rSOCs, as well as to introduce co-electrolysis as a third operating mode to supply $\mathrm{CO}$ and $\mathrm{H}_{2}$ to, e.g., industrial processes or refineries [13]. The heat can indeed be used to combine SOEC hydrogen generation with external steam-reforming, in which case low carbon footprint methane supply is guaranteed by the gas grid infrastructure [14].

All the above-discussed promising application-oriented features encourage rSOC developers and governmental agencies to strengthen research efforts to overcome the main challenges, such as short lifespan and the need to mitigate both operating- and degradation-related faults. On the other hand, recent demonstration activities [15] indicated how running rSOCs on hydrogen only to meet microgrid electricity demands can definitely help to achieve short/medium-term successful market penetration of such devices. An increased interest has emerged in the recent literature concerning the design and proper energy management of fuel cell-based RES microgrids. Torres et al. [16] proposed model predictive control to achieve optimal sharing of hydrogen-based microgrids. They also introduced constraints to limit excessive excursions of tank hydrogen levels with respect to reference targets. The need for appropriately controlling the hydrogen tank level is accounted for also in [17], where reversible proton exchange membrane technology is proposed. In this case, such an aspect was addressed by fixing a lower level threshold, beyond which other power sources, which the reversible PEM (rPEM) is integrated with, are turned on to avoid over-emptying the hydrogen tank.

In the current paper, the focus is on the development of a low-computational burden optimization tool aimed at the preliminary design of an RES microgrid integrated with an $\mathrm{H}_{2}$ fed rSOC device. A key aspect of the rSOC-RES coupling lies in the acquired energy-resiliency characteristics [18]; the stored hydrogen might guarantee an appreciable autonomy from the public network in cases of malfunction or load shedding. Therefore, the current study pays particular attention to the optimal management of the chemical energy stored in the hydrogen tank, with constraints on the initial, final, maximum, and minimum state of charge. The main optimization results can therefore be referred 
to as useful guidelines, to be taken into consideration when developing component-level control strategies for the entire balance of plant (BoP), as well as when the aim is to carefully and cost-effectively select materials and types of key components such as photovoltaic panels, wind turbines, batteries, hydrogen tanks, etc. It is worth here remarking how in the literature some contributions dealing with aspects similar to the above ones are available. Raj and Chanana [19] proposed advanced fuel cost minimization-based management of an islanded microgrid comprising wind turbine, photovoltaic panels (PV), a microturbine, a diesel generator, and a battery bank. Their main objective was to optimize fuel consuming device scheduling for an already designed system configuration. Specific activities were developed in [20] to ensure stable power supply of RES microgrids in rural areas. The importance of system resiliency and energy security was suitably addressed in [21], via the development of a remote ZigBee-communications-based energy management tool. Dynamic stability operation was addressed once again by Luo et al. [6], this time including rSOC into a highly integrated renewable-based hybrid energy generator. As clarified later on, the main novelty of the current article with respect to the above contributions lies in the optimization task, which was proven suitable to simultaneously address optimal system sizing and proper islanded-oriented and resilient management of the rSOC system that the renewable microgrid is integrated with. Moreover, when compared with a previous contribution from the authors [22], the current paper focuses on the development of an rSOC microgrid for residential uses, thus referring to the typical electric load demand of households while suitably accounting for the impact of weather uncertainties (e.g., clouding effects, wind speed limits) on renewables power contribution. Moreover, substantial discussion is provided on the compromise to be found between self-sufficiency targets and hydrogen tank size exploitation levels.

The article is organized as follows. The characteristics of the selected case study are presented and discussed in Section 2, in view of its subsequent integration with the rSOC device. Afterwards, Section 3 describes the adopted modeling approach, emphasizing its simplicity to enhance the subsequent constrained optimization phase. The outcomes of the latter are presented and discussed in Section 4 . Finally, the concluding remarks are given, aimed not only at confirming the economic viability of the proposed microgrid, but also at stressing the flexibility in meeting different loads, as well as the useful resilient features rSOC integration introduces.

\section{Plant Description}

The selected case study consists of a residential complex served by the following electric power sources: photovoltaic panels (PVs); vertical axis wind turbines (WT); hydrogen storage tank (HST); and an rSOC system. Figure 1 illustrates a simplified plant scheme, where the power demand coming from the residential complex is primarily met by the WT and PVs. Whenever the PV and WT yields overcome the above-mentioned electricity demand, the resulting excess power is converted into hydrogen by rSOCs (i.e., SOEC mode). The produced fuel gets stored in the HST for subsequent use, particularly when PV and WT contribution is lower than current demand. The inverters, which are necessary to perform DC-AC conversion, are also shown in the figure. The proposed rSOC-based renewable microgrid can be applied for residential distributed generation (as an islanded microgrid, particularly when public grid connection is missing), as well as to supply hydrogen to industrial processes and refueling stations. Figure 2 shows the average daily trajectory of electricity demand $\left(P_{\text {demand }}\right)$. Aimed at guaranteeing appreciable islanded potential, rSOC-based microgrids must be designed so as to be self-sufficient. Therefore, beyond meeting load demand in cases of PV and WT energy shortage, the HST shall be designed in such a way as to provide appreciable self-sufficiency in the case of a long-lasting lack of other source contribution (e.g, due to system failures, relevant maintenance operation, and so on). 


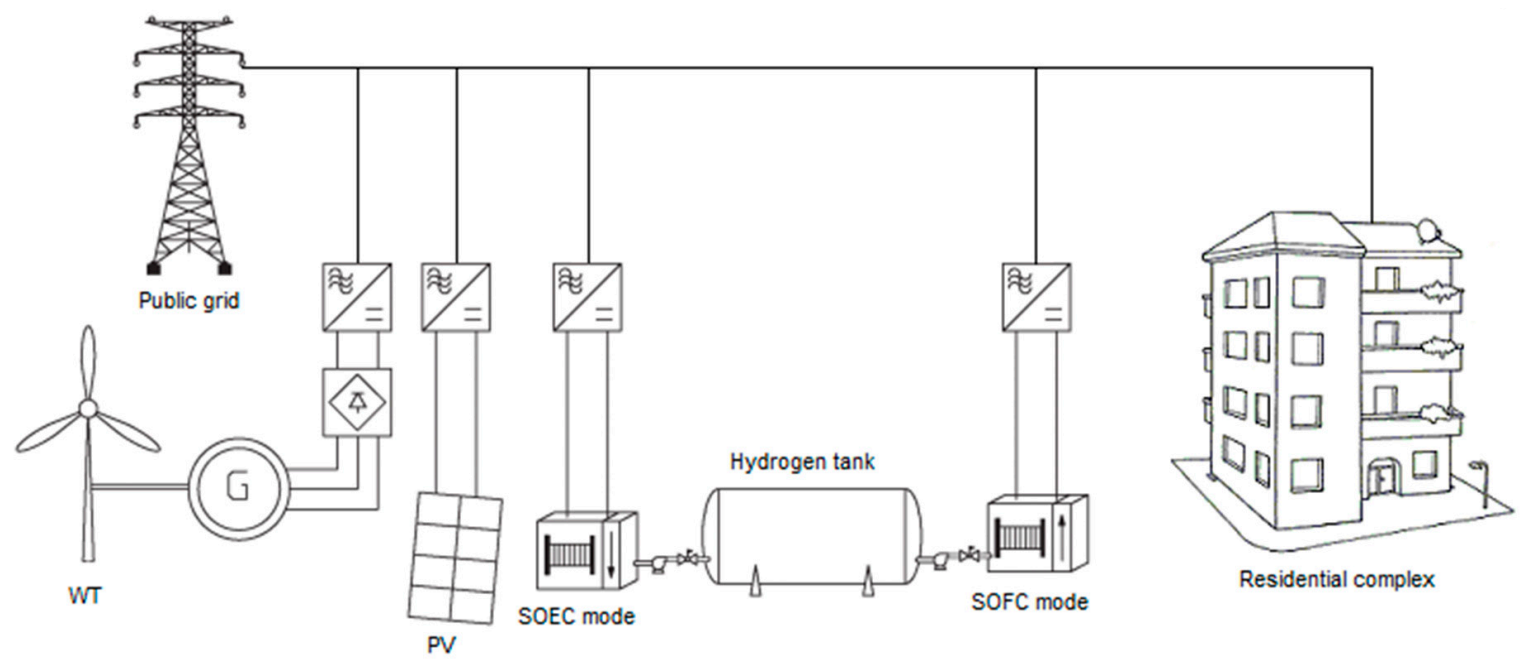

Figure 1. Simplified plant schematic, adapted from [23], including the reversible solid oxide (rSOC)-based renewable microgrid, connection to the public grid and served residential complex. It is worth remarking here that all acronyms appearing in the above figure are explained in the nomenclature section at the end of the paper.

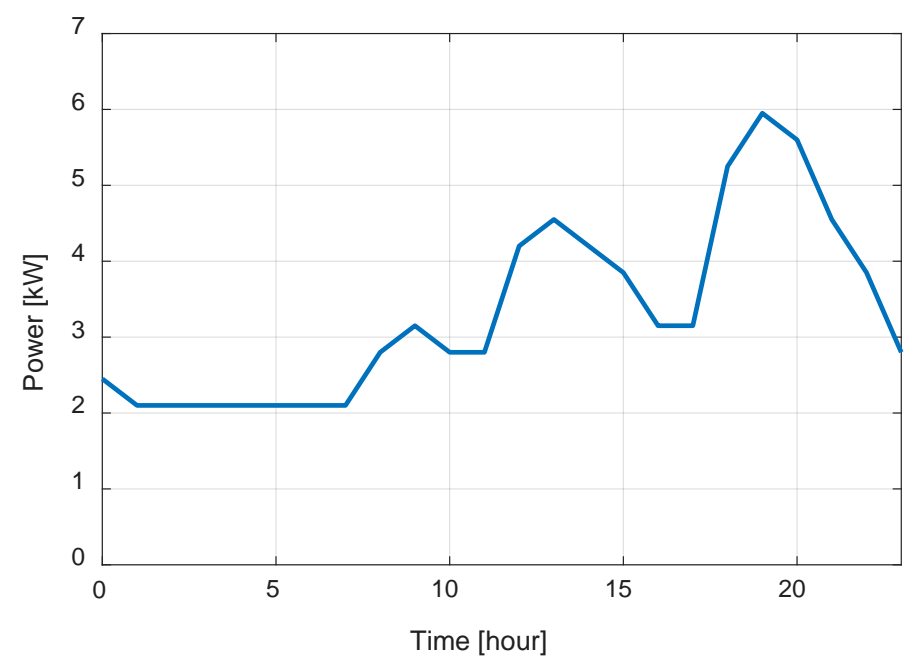

Figure 2. Electricity load demand for the entire residential complex, consisting of seven apartments. The illustrated trajectory was initially extracted from 24 and then adapted to suitably represent the average daily profile of dwelling electricity demand [24].

As for the photovoltaic panels, the choice fell on the panels described in [25], which are high-performance polycrystalline units, connected to the load network through a DC/AC inverter (see Figure 1). On the other hand, in order to have a lower cut-in wind speed, vertical axis technology was adopted for wind turbines [26].

Table 1 provides the main technical specifications for the assumed PV and WT modules, which are referred to when running the optimal sizing procedure, as discussed later on in Section 3.2). Differently from the RES, for the rSOC system the energy conversion performance, in both SOFC and SOEC operation, that correspond to maximum power operation were assumed by referring to the relevant contribution found in the literature [27].

For the electrical storage system, the most widely adopted performance index, i.e., rSOC round-trip efficiency (RTE), is expressed as follows [28]:

$$
\mathrm{RTE}_{\mathrm{rSOC}}=\frac{\left(V_{\mathrm{SOFC}} \cdot I_{\mathrm{SOFC}}-P_{\mathrm{BOP}, \mathrm{SOFC}}\right) \cdot \Delta t_{\mathrm{SOFC}}}{\left(V_{\mathrm{SOEC}} \cdot I_{\mathrm{SOEC}}+P_{\mathrm{BOP}, \mathrm{SOEC}}\right) \cdot \Delta t_{\mathrm{SOEC}}}
$$


where $V_{\mathrm{SOFC} / \mathrm{SOEC}}$ and $I_{\mathrm{SOFC} / \mathrm{SOEC}}$ are the fuel cell voltage and current, respectively, and $\Delta t_{\mathrm{SOFC} / \mathrm{SOEC}}$ is the overall operating time in SOFC/SOEC mode. $P_{\mathrm{BOP}}$ terms in Equation (1) are representative of the typical ancillary power absorptions (mainly due to the air blower) of a generic rSOC system [29].

Table 1. PV, WT, and location specs/info.

\begin{tabular}{cccc}
\hline Photovoltaic Panels [25] & Module power: $270 \mathrm{~W}$ & Efficiency: $16 \%$ & Dimensions: $1940 \times 992 \times 40 \mathrm{~mm}$ \\
\hline Wind Turbine [26] & $\begin{array}{c}\text { Nominal single turbine } \\
\text { power: } 3.6 \mathrm{~kW}\end{array}$ & $\begin{array}{c}\text { Cut-in/off wind speed: } \\
1.5 / 25 \mathrm{~m} / \mathrm{s}\end{array}$ & Nominal wind speed: $10 \mathrm{~m} / \mathrm{s}$ \\
\hline Location & $\begin{array}{c}\text { Policastro Bussentino } \\
\text { (SA) }\end{array}$ & Latitude: $40^{\circ} 03^{\prime} 60.00^{\prime \prime} \mathrm{N}$ & \\
\hline
\end{tabular}

\section{Methodological Approach}

The modeling and optimization tools, as developed and deployed in the proposed preliminary design of an rSOC-based renewable microgrid, are synthetically described and motivated hereinafter. It is worth remarking here how the main objective in designing the HST is to find the best compromise between costs and energy resiliency.

\subsection{Models Description}

In the following subsections, the PV and WT yield estimation methods and the simplified sizing-oriented modeling of an $\mathrm{rSOC}$ are proposed, mainly aimed at guaranteeing the best compromise between precision and computational time when executing constrained-optimization algorithms.

\subsubsection{PV Yield Estimation}

Insolation and wind profiles of a given location were retrieved from the public domain. The optimization analysis was particularly focused on the simulation of a specific case study in the location of Policastro Bussentino (SA) (see Table 1), characterized by relatively high average contributions of insolation and wind. As for the former yield, the following formula was adopted [22]:

$$
\left\{\begin{array}{l}
P_{\mathrm{pv}}=\eta_{\mathrm{PV}} \cdot A_{\mathrm{PV}} \cdot 1.1 \cdot 1366 \cdot 0.7^{\mathrm{AM}^{0.678}} \cdot \cos (z) \cdot \gamma \\
\mathrm{AM}=\frac{1}{\cos (z)} \text { if } z<75^{\circ} ; \mathrm{AM}=\frac{1}{\cos (z)+0.50572 \cdot(96.07995-z)^{-1.6364}} z \geq 75^{\circ} \\
\cos (z)=\sin (\delta) \cdot \sin (\varphi)+\cos (\delta) \cdot \cos (\varphi) \cdot \cos (\omega) ; \omega=2 \pi \cdot \frac{12-t}{24} ; \delta=0.4093 \cdot \sin \left(2 \pi \cdot \frac{284+\text { day }}{365}\right)
\end{array}\right.
$$

It is worth remarking how Equation (2) is valid for horizontal panels. The unavoidable losses [30] due to bad weather conditions (e.g., rainy and cloudy days) are here accounted for through the $\gamma$ factor shown in the first Equation (2), which is evaluated on a monthly basis by comparing model outputs with experimental values acquired for the selected location from [31].

\subsubsection{Modeling of Wind Turbine Power}

The annual wind speed trajectory was found for 2011 in [32]. Then, the corresponding power generated by WT is estimated via Equation (3), whose details can be retrieved from the literature [33], and referring to Table 1 data. Once again, it is worth remarking how the modeling approach was adopted coherently with the objective of developing an optimization tool aimed at preliminarily designing an rSOC-based microgrid capable of guaranteeing appreciable self-sufficiency characteristics, which in turn would allow for the meeting of energy resiliency requirements e.g., in remote areas.

$$
\left\{\begin{array}{ll}
P_{\mathrm{WT}}=P_{\mathrm{WT}, n} \frac{V^{2}-V_{c i}^{2}}{V_{n}^{2}-V_{c i}^{2}} & V_{c i} \leq V \leq V_{n} \\
P_{\mathrm{WT}}=P_{\mathrm{WT}, n} & V_{n}<V \leq V_{c o} \\
0 & V \leq V_{c i} \text { and } V \leq V_{c o}
\end{array},\right.
$$




\subsubsection{Literature-Derived Model of rSOC Energy Conversion Performance}

Equations (4) and (5) are used to evaluate, as a function of the efficiency in the current operating mode, the rSOC fuel production/consumption:

$$
\begin{gathered}
\dot{m}_{\mathrm{H}_{2}, \mathrm{SOEC}}\left[\mathrm{kg} \cdot \mathrm{s}^{-1}\right]=\frac{\eta_{\mathrm{SOEC}} \cdot\left(V_{\mathrm{SOEC}} \cdot I_{\mathrm{SOEC}}+P_{\mathrm{BOP}, \mathrm{SOEC}}\right)}{\mathrm{LHV}_{\mathrm{H}_{2}}}=\frac{0.64 \cdot\left(P_{\mathrm{PV}}+P_{\mathrm{WT}}-P_{\mathrm{demand}}\right)}{\mathrm{LHV}_{\mathrm{H}_{2}}} \text {, if } P_{\mathrm{demand}} P_{\mathrm{PV}}+P_{\mathrm{WT}} \\
\dot{m}_{\mathrm{H}_{2}, \mathrm{SOFC}}\left[\mathrm{kg} \cdot \mathrm{s}^{-1}\right]=\frac{\left(V_{\mathrm{SOFC}} \cdot I_{\mathrm{SOFC}}-P_{\mathrm{BOP}, \mathrm{SOFC}}\right)}{\mathrm{LHV} V_{\mathrm{H}_{2}} \cdot \eta_{\mathrm{SOFC}}}=\frac{P_{\mathrm{demand}}-P_{\mathrm{WT}}-P_{\mathrm{pv}}}{L V_{\mathrm{H}_{2}} \cdot 0.7} \text {, if } P_{\mathrm{demand}} \geq P_{\mathrm{PV}}+P_{\mathrm{WT}}
\end{gathered}
$$

It is worth noting that a conservative estimation of effective $\mathrm{RTE}_{\mathrm{rSOC}}$ is performed, that is to say that all the SOEC heat demand [29] is met by burning hydrogen. Assuming 0.95 burner efficiency, the above operating strategy causes the original $\eta_{\text {SOEC }}$ value, i.e., 0.76 in 28 , to reduce down to 0.64 (see Equation (4)).

The above introduced rSOC efficiency values [27] correspond to the nominal operating point (i.e., $28 \mathrm{~kW}$ of electric power) of a high-pressure operating rSOC system. In this work, it is assumed that such values can be safely extended to different rSOC sizes of the same technology, provided that:

- The rSOC is operated at constant power in both SOEC and SOFC mode;

- The assumed efficiency data are scalable up or down to the size determined by the optimization task, as described in see Section 3.2.

In order to cope with the first assumption above, more detailed sizing analyses shall be performed, particularly aimed at assessing the opportunity of integrating the proposed rSOC unit with appropriate hybridizing devices, such as super-capacitors and batteries, to suitably manage highly fluctuating power requests [22]. This aspect is of particular relevance as it is well known how abrupt and frequent changes in operating condition may be very detrimental to SOC units as a consequence of the induced dangerous thermal-stresses [34].

The daily variation of $\mathrm{HST}$ state of charge $\left(\mathrm{SOC}_{\mathrm{HST}}\right.$, intended as the ratio between actual and maximum hydrogen mass storage $m_{\mathrm{H} 2, \mathrm{HST}}$ ) is estimated as follows:

$$
\mathrm{SOC}_{\mathrm{HST}}(\text { day })=\mathrm{SOC}_{\mathrm{HST}}(\text { day }-1)+\frac{\int_{0}^{24 \cdot 3600} \dot{m}_{\mathrm{SOEC}, d a y} d t-\int_{0}^{24 \cdot 3600} \dot{m}_{\mathrm{SOFC}, d a y} d t}{m_{\mathrm{H} 2, \mathrm{HST}}}
$$

\subsubsection{Economic Data and Analysis}

In this study, the simple payback (PB) was selected to perform techno-economic feasibility assessment of the rSOC-based renewable microgrid:

$$
\mathrm{PB}=\frac{\mathrm{TC} \times(1+\mathrm{IC})-\mathrm{TD}}{\mathrm{ABC}-\mathrm{MC}},
$$

where: (i) TC is total microgrid cost, evaluated by including all main component costs (i.e., PV, WT, rSOC, HST), (ii) IC is the installation cost, here assumed equal to 10\% of the TC; (iii) MC is the annual maintenance cost (i.e., under the hypothesis it equals 3\% of TC; (iv) TD is the tax deduction, assumed equal to $50 \%$ of TC, according to Italian governmental rules [35]) and (v) ABC is the annual bill cost, which should be paid by involved owners without installing the proposed RES + rSOC microgrid. Since the plant is grid-independent, the latter variable is considered a revenue, here estimated assuming that the average cost of energy (in Italy) is $0.25 € / \mathrm{kWh}$.

For the analysis of the photovoltaic panels and wind turbines costs, specific manufacturer data-sheets were considered (see corresponding data in Table 2). Finally, the cost of reversible solid oxide fuel cells was set to $340 € / \mathrm{kW}$ [36], while the cost of storing the hydrogen gas was assumed equal to $400 € / \mathrm{kg}$ [37]. 
Table 2. Summary of unit costs.

\begin{tabular}{cc}
\hline Component & Unit Cost \\
\hline PV: (panel + inverter) & $(600+217) € / \mathrm{kW}$ \\
WT: (tower + rotor + inverter + grid-on controller) & $(504+1108+635+266) € / \mathrm{kW}$ \\
\hline
\end{tabular}

\subsection{Constrained Optimization Algorithm}

The microgrid sizing was carried out via a constrained optimization task, here expressed by Equation (8). The optimization task was implemented and run in the Excel ${ }^{\circledR}$ spreadsheet environment [38]. Particularly, the default resolution method (i.e., the generalized reduced gradient (GRG) [39]) was adopted. Beyond minimizing the simple pay-back time, another key objective was to suitably account for the impact of renewables and rSOC interaction in terms of $\mathrm{SOC}_{\mathrm{HST}}$ daily variation. As for the latter aspect, the goal was to guarantee, through the constraint $\mathrm{c}_{4}$ defined later on in this section, that final (i.e., end day of the year) and initial (i.e., first day of the year) tank filling levels do not differ, thus ensuring year-through charge sustaining management of HST. The variables to be optimized are: nominal PV power $\left(P_{\mathrm{PV}}\right)$, nominal wind turbines power $\left(P_{\mathrm{W}}\right)$, and $m_{\mathrm{H} 2, \mathrm{HST}}$ :

$$
\min _{P_{\mathrm{PV}}, P_{\mathrm{W}}, m_{\mathrm{H}}, \mathrm{HST}} \mathrm{PB},
$$

The optimization is subject to the following $c i$ constraints:

$\left(c_{1}\right) \mathrm{ABC} \geq \mathrm{MC} ;$

$\left(c_{2}\right) \mathrm{SOC}_{\mathrm{HST}}<0.95$

$\left(c_{3}\right) \mathrm{SOC}_{\mathrm{HST}}>0.15$

$\left(c_{4}\right) \max \left(P_{\mathrm{rSOC}}\right)=P_{\mathrm{PV}, n}+P_{\mathrm{W}, n} ;$

$\left(c_{5}\right) \mathrm{SOC}_{\mathrm{HST}}\left(\right.$ day $\left._{i}\right)=\mathrm{SOC}_{\mathrm{HST}}\left(\right.$ day $\left._{f}\right)$

where $c_{4}$ ensures that renewable energy never gets wasted. It is also worth remarking here that day and $d a y_{f}$ in the $c_{5}$ relationship relate to January the 1st and December 31st, respectively, whereas $c_{2}$ and $c_{3}$ shall hold valid for the entire year, thus limiting both hydrogen shortage and excess. This will in turn avoid, respectively, running out of fuel in the case of sudden grid unavailability, and wasting renewable energy in the case of unpredicted surplus. As for constraint $c_{4}$, it is worth anticipating here that the baseline optimization outcome (i.e., the one meeting the $c_{3}$ constraint, as detailed in the section below) ensures fully avoiding any waste of renewables, since the ratio between yearly maximum renewable power surplus and SOEC nominal power is safely limited below $90 \%$ (i.e., $89.7 \%$ ).

\section{Presentation and Discussion of Optimization Results}

In this section, the outcomes of the constrained optimization task (see Section 3.2) are presented and discussed. Table 3 shows the sizes of the main microgrid components and the minimum PB obtained through the Excel solver (with default settings). Figure 3, which shows the simulated $\mathrm{SOC}_{\mathrm{HST}}$ trajectory, demonstrates the reliability of the HST charge sustaining management resulting from the constrained optimization procedure.

Table 3. Constrained optimization (see Section 3.2) outcomes in terms of costs (€) and nominal microgrid component power/size.

\begin{tabular}{ccccccccc}
\hline $\begin{array}{c}\text { Plant } \\
\text { Cost }(\boldsymbol{\epsilon})\end{array}$ & $\begin{array}{c}\text { Installation } \\
\text { Cost }(\boldsymbol{\epsilon})\end{array}$ & $\begin{array}{c}\text { Tax } \\
\text { Deductions } \\
(\boldsymbol{\epsilon})\end{array}$ & $\begin{array}{c}\text { Annual } \\
\text { Bill Cost } \\
(\boldsymbol{\epsilon})\end{array}$ & $\begin{array}{c}\text { Maintenance } \\
\text { Cost }(\boldsymbol{\epsilon})\end{array}$ & $\begin{array}{c}\text { Nominal } \\
\boldsymbol{P}_{\mathbf{P V}}(\mathbf{k W})\end{array}$ & $\begin{array}{c}\text { Nominal } \\
\boldsymbol{P}_{\text {WT }}(\mathbf{k W})\end{array}$ & $\begin{array}{c}\text { HST H } \mathbf{H}_{\mathbf{2}} \\
\text { Mass (kg) }\end{array}$ & $\begin{array}{c}\text { PB } \\
(\text { Years) }\end{array}$ \\
\hline 84,580 & 8458 & 42,290 & 7281.8 & 2537.4 & 8.906 & 15.658 & 74.163 & 10.696 \\
\hline
\end{tabular}




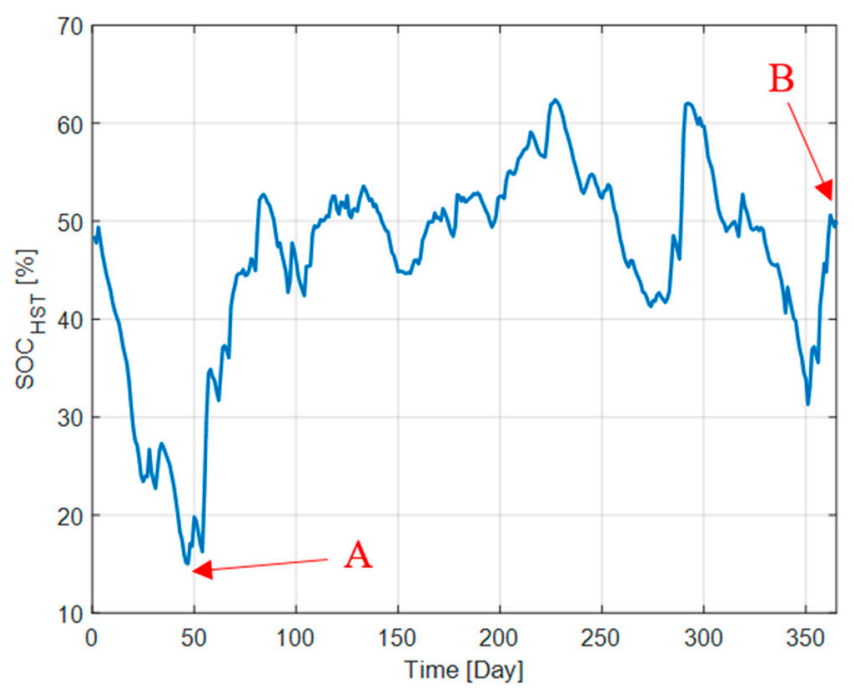

Figure 3. Simulated year-through solid oxide cell (SOC) $)_{\mathrm{HST}}$ trajectory. A and B labels highlight minimum and final hydrogen tank levels, respectively, which are used later on in the paper to assess the potential self-sufficiency range achieved by the optimal renewable rSOC-based microgrid design.

According to Table 3, the values of nominal powers and of the hydrogen storage tank size determine the plant cost, while the other costs are obtained from the hypotheses listed in Section 3.1.4. On the other hand, Equation (7) allows obtaining the payback value to be included in the cost function (see Equation (8)). The optimal value yielded on output by the constrained-optimization task interestingly sets to 10.7 years, which increases by $15 \%$ if rSOC capital expenditures (CAPEX) costs increase up to $680 €$ per $\mathrm{kW}$.

Figures 4 and 5 show the simulated photovoltaic and wind power supply trends, indicating the physical coherence of the assumed simplifying hypotheses and modeling approach, accounting for both daytime and seasonal effects. It particularly demonstrates how the selected location is well served by both insolation and wind energy sources, as the lack of the former is fully compensated by the latter availability and vice versa, depending on the time of day. As for the effective contribution of renewable sources, Figure 5 highlights how WT power is often much lower than its corresponding nominal value (see Table 3), whereas PV panels appear better exploited from this point of view, as shown in Figure 4. In order to deepen such an aspect, the distribution of WT power contribution throughout the year shall be analyzed. Particularly, the cumulative curve associated with such a distribution, shown in Figure 6 , along with yearly wind speed profile, indicates that WTs often work in off-design conditions. The latter aspect can surely be of high importance in terms of plant cost impact. It is indeed expected that grid-connected microgrids shall be preferred in such locations. Nevertheless, the objective of providing a methodology capable of yielding on output a potentially fully grid-independent microgrid configuration was advantageous. Of course, the opportunity to rely on more favorable locations (in terms of wind speed availability and exploitability) is expected to play an important role in obtaining more cost-effective designs. 


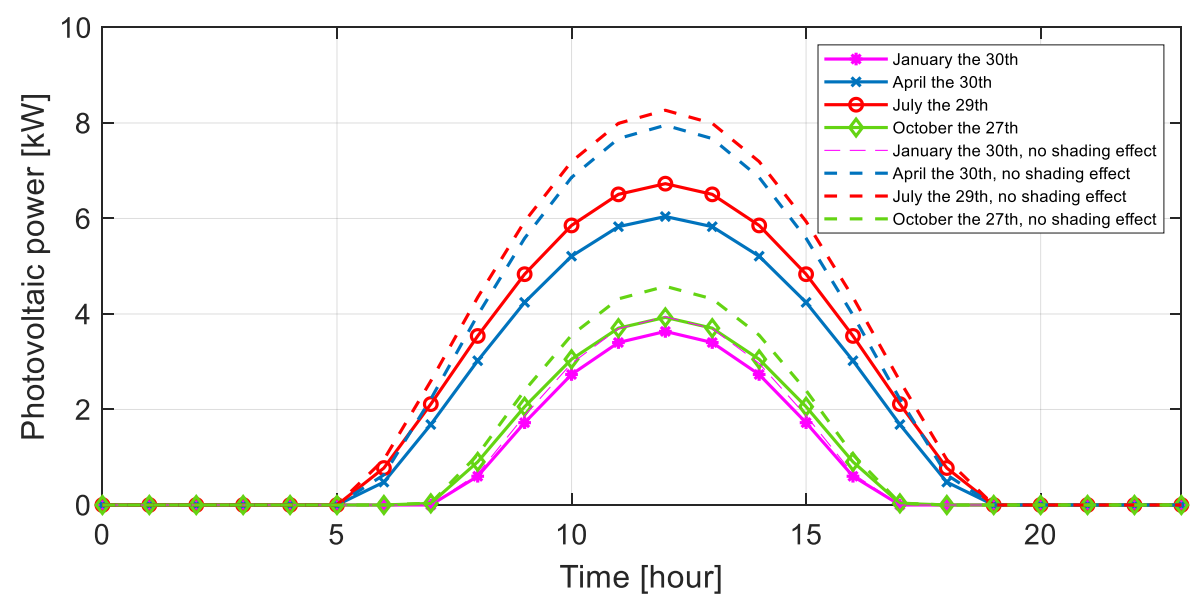

Figure 4. Hourly photovoltaic power.

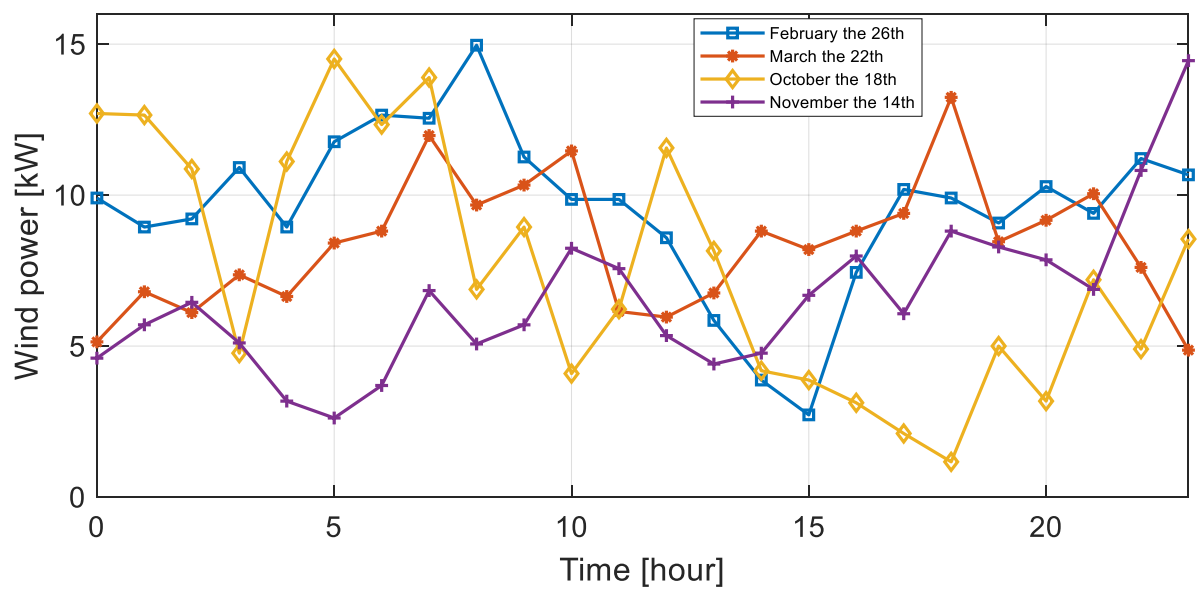

Figure 5. Hourly wind turbine power.

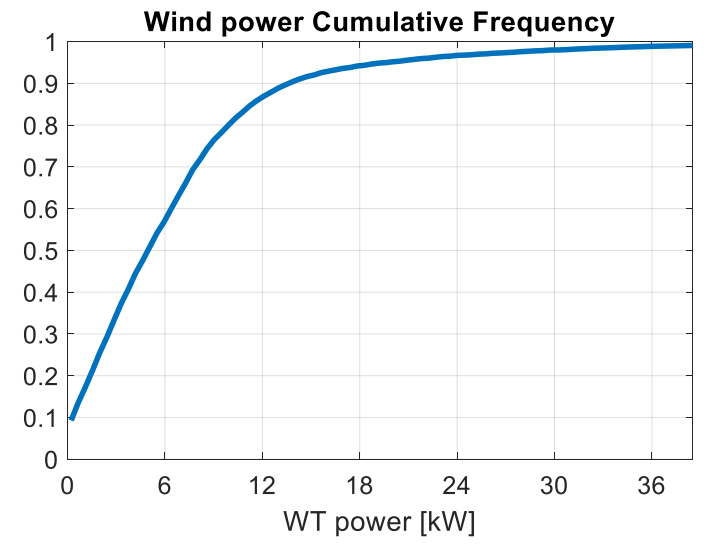

(a)

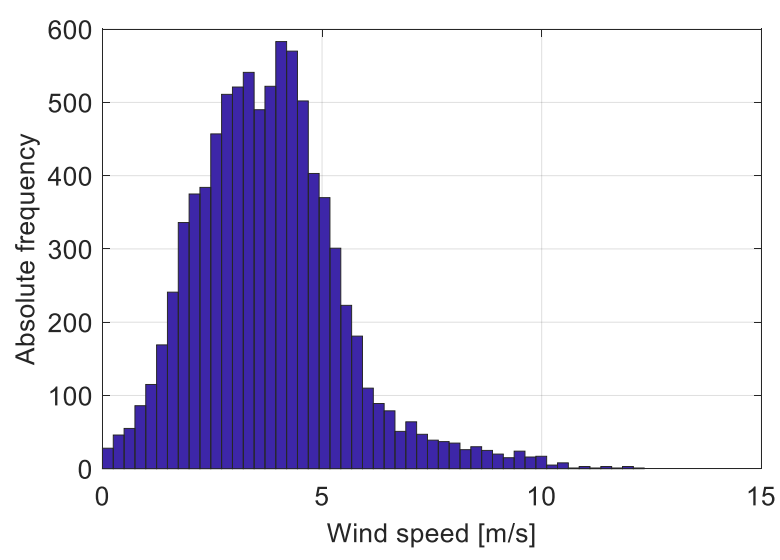

(b)

Figure 6. (a) Cumulative curve associated with the wind power distribution resulting from applying the model expressed by Equation (3) to the selected microgrid location (see Table 1); (b) Histogram of the yearly wind speed profile.

In the event that neither grid electricity nor renewable energy are available, it is possible to calculate the resiliency that the microgrid rSOC guarantees in terms of self-sufficiency, considering electricity demand (see Figure 2), the hydrogen consumed in SOFC mode (see Equation (5)), and the storable chemical energy in the HST (see Table 3). Assuming that the load profile is constant and equal 
to that already considered previously, it is possible to estimate the self-sufficiency of the plant at time $t$ in the case of lack of renewable electricity production, as follows:

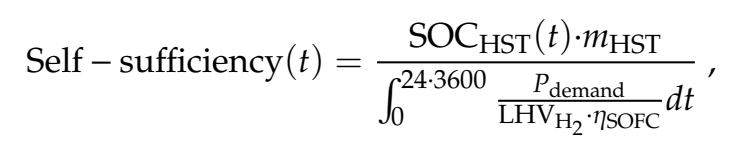

The previous equation allows the assessment of whether the HST is capable of fully meeting user request for a time interval ranging from almost 1.62 days, i.e., in correspondence with the minimum HST state of charge labeled as point A in Figure 3, up to 5.4 days, this latter being associated with a half full HST (i.e., point B). Such an outcome confirms the highly promising resilient features the proposed renewable rSOC-based microgrid can guarantee.

In order to further investigate the impact of design criteria and assumptions on constrained optimization outcomes and, in turn, on the real world implications of different configuration scenarios, a parametric analysis was carried-out by varying the constraint (see Figure 7) on minimum $\mathrm{SOC}_{\mathrm{HST}}$ (i.e., $\mathrm{SOC}_{\mathrm{HST} \text {,min }}$ from now on) between $5 \%$ and $25 \%$. These effects were assessed by running two further optimization analyses, whose outcomes are analyzed and discussed against the previously presented baseline (i.e., the one corresponding to $\mathrm{SOC}_{\mathrm{HST}, \mathrm{min}} \geq 15 \%$ ). Figures 7 and 8 display these results and provide interesting indications. Relaxing the constraint on minimum hydrogen storage (e.g., setting $\mathrm{SOC}_{\mathrm{HST} \text {,min }} \geq 5 \%$ ) causes plant cost, simple payback, HST mass, and self-sufficiency range to reduce, as shown in Figure 7. Particularly, self-sufficiency exhibits (see Figure 8) a nonlinear relationship with $\mathrm{SOC}_{\mathrm{HST} \text {,min }}$; low $\mathrm{SOC}_{\mathrm{HST} \text {,min, }}$ obtained as mentioned before by relaxing the constraint $c_{3}$ in Section 3.2, causes the difference between the minimum and maximum range of self-sufficiency to increase. On the other hand, strengthening such constraints would determine the opposite behavior, thus allowing larger self-sufficiency independently from when the emergency event (e.g., simultaneous unavailability of RES and electricity grid) occurs. Nevertheless, considering the higher capital costs and paybacks associated with an over-strengthened $\mathrm{c}_{3}$ constraint, $\mathrm{SOC}_{\mathrm{HST}, \mathrm{min}}=15 \%$ can be selected as a suitable design criterion to achieve the best compromise between techno-economic feasibility and resiliency requirements for the investigated $\mathrm{rSOC}$ microgrid. It is also worth pointing out that $\mathrm{SOC}_{\mathrm{HST}}$ is never higher than $60 \%$, as shown in Figure 3, mainly because the designed rSOC microgrid does not necessarily interface with the electricity grid, thus making it more difficult to cope with $\mathrm{SOC}_{\mathrm{HST} \text {,min }}$ requirements in case a small tank size is selected. Therefore, the selected design criteria, particularly those related to microgrid resiliency and self-sufficiency range, shall be revised or partially relaxed if a more effective exploitation of the HST has to be achieved, which in turn could also play a positive role in reducing overall plant CAPEX. To further support the above comment, an additional optimization analysis was performed by assuming initial HST to be equal to 0.7 . It was verified that in this way the $\mathrm{PB}$ could be slightly reduced (5\%) and an almost full exploitation of the selected HST level range can be achieved, while causing, as the main drawback, maximum self-sufficiency to reduce down to four days, whereas current design criteria allows achieving up to six and a half days (see Figure 8).

As for rSOC operating conditions, it is important to remember that heat is produced in SOFC mode, thus leaving further design margins. For instance, a thermal storage unit could be included in the overall rSOC BoP, in such a way as to enable re-using the heat stored in SOFC mode to supply the necessary heat in SOEC phases. Nevertheless, such a component addition may have a negative impact on rSOC BoP complexity and would require careful attention to heat exchanger design and development, which in turn could result in higher CAPEX and complex energy management. Finally, the application under analysis could also be used to supply a hydrogen car refueling station. Considering the Toyota Mirai specifications [40] and particularly the fuel economy (as high as $100 \mathrm{~km} / \mathrm{kg}$ ) and tank capacity (5 kg), the designed HST (see Table 3), if assumed half-full, could provide up to seven cars with the amount of fuel required to drive a distance of $500 \mathrm{~km}$. 


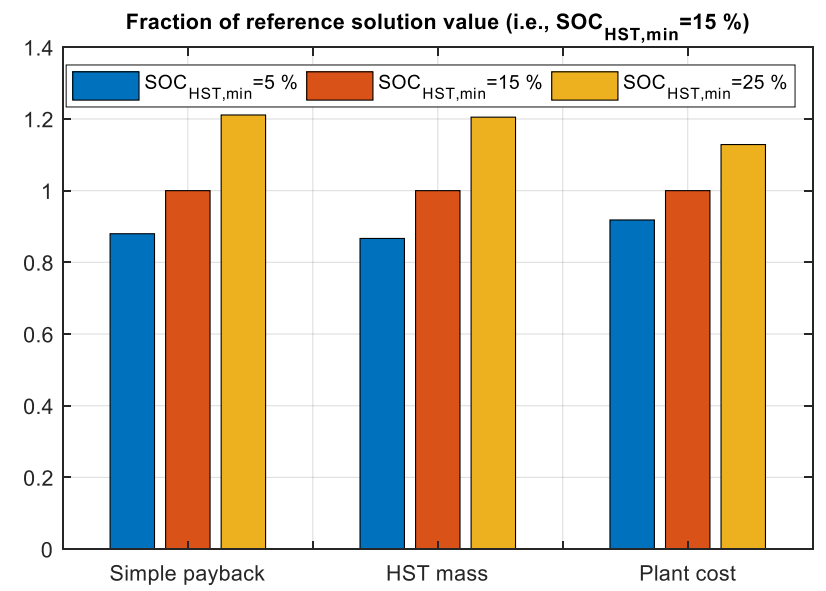

Figure 7. Comparison between three renewable rSOC microgrid configurations resulting from the application of the constrained optimization algorithm to three scenarios, each one characterized by a different $c_{3}$ constraint (see Section 3.2).

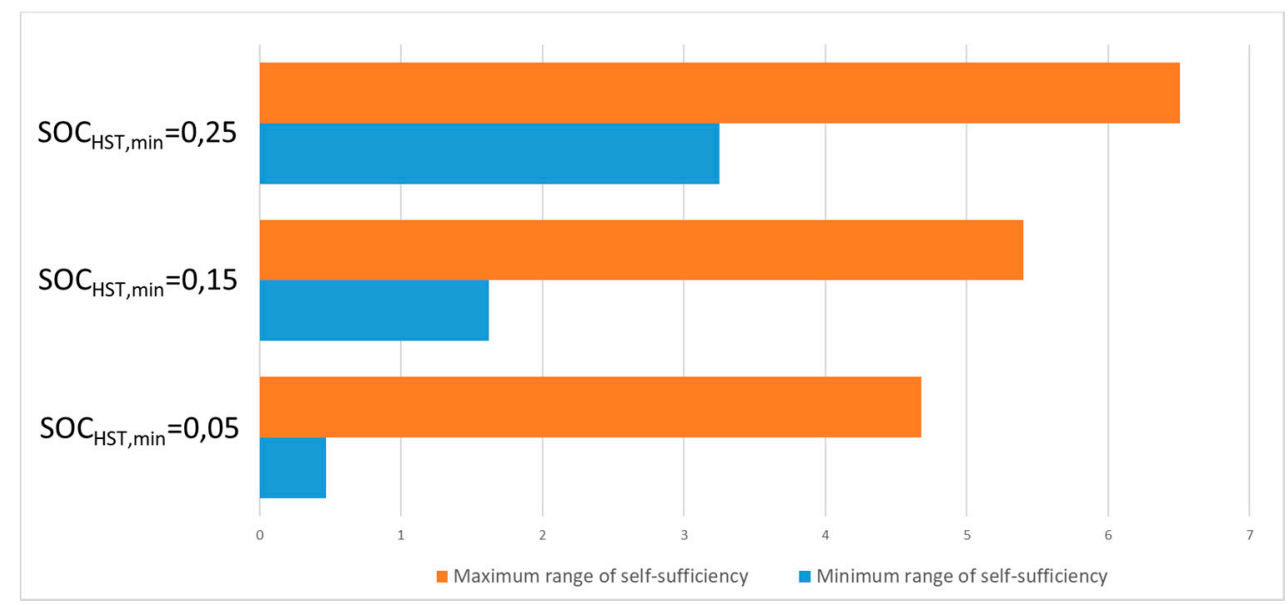

Figure 8. Variation of self-sufficiency ranges as a function of selected $c_{3}$ constraint (see Figure 7 caption and Section 3.2).

\section{Conclusions}

The main target of the presented research was the development of models and procedures aimed at preliminarily designing and evaluating the technical feasibility of an rSOC-based renewable microgrid, for both residential power supply (even in islanded configuration) and hydrogen supply to industrial processes and refueling stations. Reaching these goals can be reached by the main innovation introduced, namely the achievement of charge sustaining energy management for the hydrogen storage tank. This strategy ensures that the tank will neither get filled-up nor ever become empty during the year, thus allowing the full exploitation of the available RES plant. It was estimated that the investement could be fully recovered in about ten years, while the resulting optimal RES plant sizes appear reasonable with respect to targeted average load demand. Beyond confirming the high techno-economic potential of an adequate combination of RES and rSOC, optimization outcomes also demonstrate the possibility, by adopting the proposed procedure, of simultaneously addressing the interconnected needs of optimal system design and rSOC management.

The specific analysis, carried-out on the impact of strengthening the constraint on minimum hydrogen storage (i.e., by imposing higher minimum admissible hydrogen levels in the tank), indicated that larger self-sufficiency (i.e., the capacity of meeting load demand independently from RES and grid availability) can be attained, while admitting an acceptable CAPEX increase. Moreover, larger self-sufficiency, which in turn determines larger hydrogen storage tanks, introduces further deployment 
opportunities, such as the coupling of residential loads to refueling (i.e., for hydrogen-fed cars) and recharging station (i.e., for electric vehicles) demands. In this way, a highly potential synergy between clean stationary generation and sustainable mobility can be achieved, thus also contributing, through a leveraging effect, to speeding up the development of effective and properly functioning comprehensive and low carbon footprint smart energy systems. Research follow-ups, beyond including additional electrical and thermal loads to be met by the rSOC-based microgrid, will focus on refining the techno-economic feasibility assessment. Particularly, the total cost of ownership will be assessed, including the impact of interest rates, allowing a more accurate comparison between proposed renewable exploitation and other technology solutions. Furthermore, more detailed models will be used to perform model-based definition of on-field applicable control strategies, and to address the relevant aspects of rSOC thermal management and related additional degrees of freedom, in terms of additional loads (i.e., thermal) being met, as well as the opportunity to store and re-use (during the SOEC phase) the heat produced in SOFC mode. Lastly, both rSOC battery hybridization and interaction with the electricity grid will be explored to ensure acceptable self-sufficiency capabilities, while improving the exploitation of available hydrogen storage tanks.

Author Contributions: The following specific work share took place: Conceptualization, M.S., A.A. and G.N.; Data curation, A.A.; Formal analysis, M.S. and G.N.; Investigation, M.S., A.A. and G.N.; Methodology, M.S., A.A. and G.N.; Software, M.S., A.A. and G.N.; Supervision, M.S.; Writing—original draft, A.A. and G.N.; Writing一review \& editing, M.S. and A.A.

Funding: This research received no external funding.

Acknowledgments: University of Salerno and MIUR are kindly acknowledged for the support provided.

Conflicts of Interest: The authors declare no conflict of interest.

\section{Nomenclature}

\begin{tabular}{|c|c|}
\hline Acronyms & \\
\hline $\mathrm{ABC}$ & Annual Bill Cost $[€]$ \\
\hline $\mathrm{AC}$ & Alternating Current \\
\hline BoP & Balance of Plant \\
\hline CAPEX & CAPital EXpenditure \\
\hline $\mathrm{CO}$ & Carbon Monoxide \\
\hline DC & Direct Current \\
\hline $\mathrm{H}_{2}$ & Hydrogen \\
\hline HST & Hydrogen Storage Tank \\
\hline IC & Installation Cost $[€]$ \\
\hline MC & Annual Maintenance Cost $[€]$ \\
\hline PB & Payback [years] \\
\hline PV & Photovoltaic Panels \\
\hline RES & Renewable Energy Sources \\
\hline rPEM & Reversible Proton Exchange Membrane \\
\hline rSOC & Reversible Solid Oxide Cells \\
\hline $\mathrm{SOC}_{\mathrm{HST}}$ & Hydrogen Storage Tank State of Charge \\
\hline $\mathrm{SOC}_{\mathrm{HST} \text {,min }}$ & Minimum Hydrogen Storage Tank State of Charge \\
\hline SOEC & Solid Oxide Electrolyzer Cell \\
\hline SOFC & Solid Oxide Fuel Cell \\
\hline TC & Total Cost $[€]$ \\
\hline TD & Tax deduction rate \\
\hline WT & Wind Turbines \\
\hline
\end{tabular}




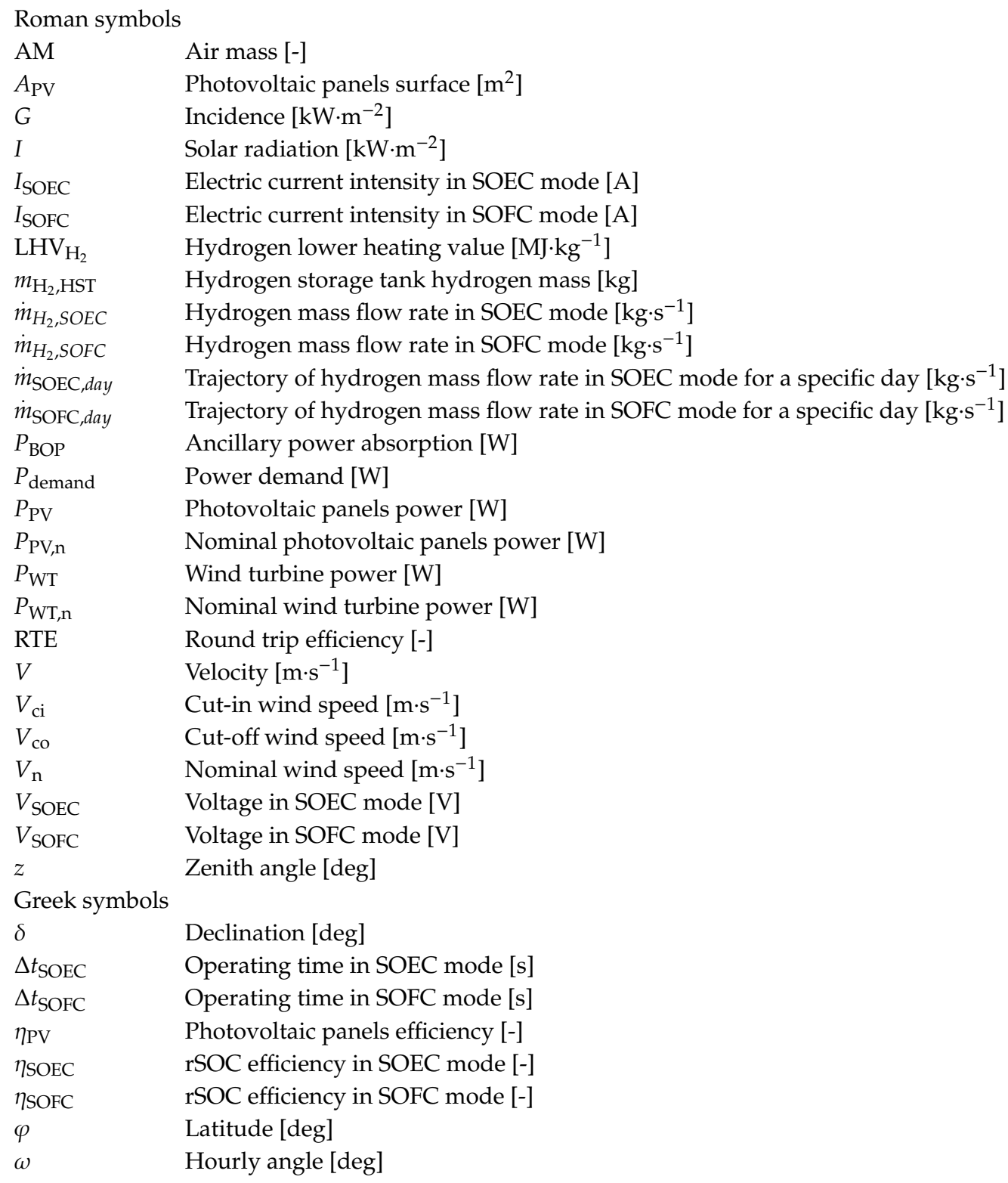

\section{References}

1. Matsumoto, T.; Kimura, K.; Nishihara, H.; Kasukabe, T.; Kyotani, T.; Kobayashi, H. Fabrication of Si nanopowder from Si swarf and application to high-capacity and low cost Li-ion batteries. J. Alloys Compd. 2017, 720, 529-540. [CrossRef]

2. Englberger, S.; Hesse, H.; Kucevic, D.; Jossen, A. A Techno-Economic Analysis of Vehicle-to-Building: Battery Degradation and Efficiency Analysis in the Context of Coordinated Electric Vehicle Charging. Energies 2019, 12, 955. [CrossRef]

3. Lystianingrum, V.; Hredzak, B.; Agelidis, V.G. Multiple model estimator based detection of abnormal cell overheating in a Li-ion battery string with minimum number of temperature sensors. J. Power Sources 2015, 273, 1171-1181. [CrossRef]

4. Hou, J.; Sun, J.; Hofmann, H. Control development and performance evaluation for battery/flywheel hybrid energy storage solutions to mitigate load fluctuations in all-electric ship propulsion systems. Appl. Energy 2018, 212, 919-930. [CrossRef]

5. Arani, A.K.; Karami, H.; Gharehpetian, G.; Hejazi, M. Review of Flywheel Energy Storage Systems structures and applications in power systems and microgrids. Renew. Sustain. Energy Rev. 2017, 69, 9-18. [CrossRef] 
6. Luo, Y.; Shi, Y.; Zheng, Y.; Cai, N. Reversible solid oxide fuel cell for natural gas/renewable hybrid power generation systems. J. Power Sources 2017, 340, 60-70. [CrossRef]

7. Wendel, C.H.; Braun, R.J. Design and techno-economic analysis of high efficiency reversible solid oxide cell systems for distributed energy storage. Appl. Energy 2016, 172, 118-131. [CrossRef]

8. Gallo, M.; Marra, D.; Sorrentino, M.; Pianese, C.; Au, S.F. A versatile computational tool for model-based design, control and diagnosis of a generic Solid Oxide Fuel Cell Integrated Stack Module. Energy Convers. Manag. 2018, 171, 1514-1528. [CrossRef]

9. Ramadhani, F.; Hussain, M.; Mokhlis, H.; Fazly, M.; Ali, J.M. Evaluation of solid oxide fuel cell based polygeneration system in residential areas integrating with electric charging and hydrogen fueling stations for vehicles. Appl. Energy 2019, 238, 1373-1388. [CrossRef]

10. Polverino, P.; D'Aniello, F.; Arsie, I.; Pianese, C. Study of the energetic needs for the on-board production of Oxy-Hydrogen as fuel additive in internal combustion engines. Energy Convers. Manag. 2019, 179, 114-131. [CrossRef]

11. Taamallah, S.; Vogiatzaki, K.; Alzahrani, F.; Mokheimer, E.; Habib, M.; Ghoniem, A. Fuel flexibility, stability and emissions in premixed hydrogen-rich gas turbine combustion: Technology, fundamentals, and numerical simulations. Appl. Energy 2015, 154, 1020-1047. [CrossRef]

12. Sorrentino, M.; Pianese, C.; Maiorino, M. An integrated mathematical tool aimed at developing highly performing and cost-effective fuel cell hybrid vehicles. J. Power Sources 2013, 221, 308-317. [CrossRef]

13. Zheng, Y.; Wang, J.; Yu, B.; Zhang, W.; Chen, J.; Qiao, J.; Zhang, J. A review of high temperature co-electrolysis of $\mathrm{H}_{2} \mathrm{O}$ and $\mathrm{CO}_{2}$ to produce sustainable fuels using solid oxide electrolysis cells (SOECs): Advanced materials and technology. Chem. Soc. Rev. 2017, 46, 1427-1463. [CrossRef] [PubMed]

14. Balcombe, P.; Brandon, N.; Hawkes, A. Characterising the distribution of methane and carbon dioxide emissions from the natural gas supply chain. J. Clean. Prod. 2018, 172, 2019-2032. [CrossRef]

15. Schwarze, K.; Posdziech, O.; Kroop, S.; Lapeña-Rey, N.; Mermelstein, J. Green Industrial Hydrogen via Reversible High-Temperature Electrolysis. ECS Trans. 2017, 78, 2943-2952. [CrossRef]

16. Garcia-Torres, F.; Valverde, L.; Bordons, C. Optimal Load Sharing of Hydrogen-Based Microgrids with Hybrid Storage Using Model-Predictive Control. IEEE Trans. Ind. Electron. 2016, 63, 4919-4928. [CrossRef]

17. Tribioli, L.; Cozzolino, R.; Evangelisti, L.; Bella, G. Energy Management of an Off-Grid Hybrid Power Plant with Multiple Energy Storage Systems. Energies 2016, 9, 661. [CrossRef]

18. FCH2JU 2014. Fuel Cells and Hydrogen Joint Undertaking: Addendum to the Multi Annual Work Plan. 2014-2020. 2014. Available online: https://www.fch.europa.eu/sites/default/files/MAWP\%20final\%20version_ endorsed\%20GB\%2015062018\%20\%28ID\%203712421\%29.pdf (accessed on 1 June 2017).

19. Raj, V.M.; Chanana, S. Fuel Cost Optimization of an Islanded Microgrid Considering Environmental Impact. J. Clean Energy Technol. 2016, 4, 120-124. [CrossRef]

20. Gao, C.; Jiao, J.; Yang, R.; Dou, Z. Power Control Strategy Design in an Islanded Microgrid Based on Virtual Frequency. In Proceedings of the 2nd IET Renewable Power Generation Conference (RPG 2013), Beijing, China, 9-11 September 2013.

21. Salas, P.; Guerrero, J.; Sureda, F. Mas Roig Mini-grid: A Renewable-Energy-Based Rural Islanded Microgrid. In Proceedings of the 2014 IEEE International Energy Conference (ENERGYCON), Cavtat, Croatia, 13-16 May 2014; pp. 975-982.

22. Sorrentino, M.; Adamo, A.; Nappi, G. Optimal Sizing of an rSOC-Based Renewable Microgrid. Energy Procedia 2019, 159, 237-242. [CrossRef]

23. Poli, D.; Giglioli, R.; Franco, A.; Filippeschi, S.; Di Marco, P.; Barsali, S. Dimostratore di Casa Attiva. Available online: http://www.enea.it/it/Ricerca_sviluppo/documenti/ricerca-di-sistema-elettrico/tecnologie-elettriche/ rds-307-122-dimostratore-casa-attiva-univ-pisa.pdf/at_download/file (accessed on 1 June 2017).

24. Maiorino, M.; Stockar, S.; Sorrentino, M.; Rizzoni, G. Modeling and Simulation of Residential Power Demand Including Transportation. In Proceedings of the ASME 2015 Dynamic Systems and Control Conference, Columbus, OH, USA, 28-30 October 2015. [CrossRef]

25. Panneau Solaire I'M SOLAR 270P. Available online: https://www.alma-solarshop.fr/panneau-i-m-solar/1021panneau-i-m-premium-270p.html (accessed on 1 July 2017).

26. Aeolos Wind Turbine. 2017. Available online: www.windturbinestar.com/3kwv-v-aeolos-wind-turbine.html (accessed on 1 July 2017). 
27. Scaltritti, M. Sistemi di Accumulo di Energia Elettrica Basati su Celle a Ossidi Solidi Reversibili (rSOC): Dimensionamento e Simulazioni Preliminari. Master's Thesis, Mechanical Engineering, Politecnico di Milan, Milan, Italy, 2016. (In Italian)

28. Wendel, C.; Kazempoor, P.; Braun, R. Novel electrical energy storage system based on reversible solid oxide cells: System design and operating conditions. J. Power Sources 2015, 276, 133-144. [CrossRef]

29. Di Giorgio, P.; Desideri, U. Potential of Reversible Solid Oxide Cells as Electricity Storage System. Energies 2016, 9, 662. [CrossRef]

30. Barelli, L.; Bidini, G.; Bonucci, F.; Ottaviano, A. Residential micro-grid load management through artificial neural networks. J. Energy Storage 2018, 17, 287-298. [CrossRef]

31. ENEA Solar Database. Available online: http://www.solaritaly.enea.it/CalcRggmmOrizz/Calcola.php (accessed on 1 May 2019).

32. Atlante Eolico-in Italian. 2011. Available online: http://atlanteeolico.rse-web.it/download_dati-IT.php (accessed on 1 August 2018).

33. Sohoni, V.; Gupta, S.C.; Nema, R.K. A Critical Review on Wind Turbine Power Curve Modelling Techniques and Their Applications in Wind Based Energy Systems. J. Energy 2016, 2016, 1-18. [CrossRef]

34. Barelli, L.; Bidini, G.; Ottaviano, A. Solid oxide fuel cell modelling: Electrochemical performance and thermal management during load-following operation. Energy 2016, 115, 107-119. [CrossRef]

35. Italian Government. DPF-Documento Programmatico di Bilancio. Available online: https:/ec.europa.eu/ info/sites/info/files/economy-finance/2019_dbp_it_it.pdfm (accessed on 1 May 2019). (In Italian)

36. Milliken, C.E.; Ruhl, R.C. Low Cost, High Efficiency Reversible Fuel Cell Systems. Proc. of the 2002 US DOE Hydrogen Program Review, NREL/CP-610-32405. Available online: https://www.nrel.gov/docs/fy02osti/ 32405b25.pdf (accessed on 1 August 2018).

37. FCH2JU. Fuel Cells and Hydrogen Joint Undertaking: The Multi Annual Work Plan. $2014-2020$. 2014. Available online: http://ec.europa.eu/research/participants/data/ref/h2020/other/legal/jtis/fch-multiworkplan_en.pdf (accessed on June 2017).

38. FrontlineSolvers. 2019. Available online: https://www.solver.com/excel-solver-algorithms-and-methodsused (accessed on 1 August 2019).

39. Lasdon, L.S.; Fox, R.L.; Ratner, M.W. Nonlinear Optimization Using the Generalized Reduced Gradient Method; Defense Technical Information Center (DTIC): Fort Belvoir, VA, USA, 1973.

40. Toyota Mirai. 2015. Available online: https://en.wikipedia.org/wiki/Toyota_Mirai (accessed on 18 August 2019). 